\title{
RENAL HOMOTRANSPLANTATION IN PEDIATRIC PATIENTS
}

BY

JOHN R. LILLY, GEOFFREY GILES, RICHARD HURWITZ, GERHARD SCHROTER, HIROSHI TAKAGI, SAMUEL GRAY, ISRAEL PENN,

CHARLES G. HALGRIMSON, AND

THOMAS E. STARZL

Reprinted from Pediatrics, Vol. 47, No. 3

March, 1971

(C) All rights reserved 


\title{
RENAL HOMOTRANSPLANTATION IN PEDIATRIC PATIENTS
}

\author{
John R. Lilly, M.D., Geoffrey Giles, M.D., Richard Hurwitz, M.D., Gerhard Schroter, M.D., \\ Hiroshi Takagi, M.D., Samuel Gray, M.D., Israel Penn, M.D., Charies G. Halgrimson, M.D., \\ and Thomas E. Starzl, M.D., Ph.D. \\ From the Departments of Surgery and Pediatrics, University of Colorado Medical Center, \\ Denver, Colorado
}

\begin{abstract}
Fifty-seven patients were treated with renal homotransplantation from $1 \frac{112}{2}$ to $7 \frac{1}{3}$ years ago; 23 patients were 12 years or younger and the other 34 patients were 13 to 18 . Family members (usually parents) were the primary donors in 45 cases. Unrelated volunteers or cadavers donated the other 12 homografts. Immunosuppression was with azathioprine and prednisone, and in some cases also with ALG. Forty-two of the 57 recipients survived for at least 1 year. Additional deaths occurred at $17 \frac{1}{2}$ and 19 months leaving 40 recipients (70.2\%) alive. Six survivors had successful retransplantation following late failure of their original homografts. Control of rejection was not particularly different than in adult cases. "Homograft glomerulonephritis" was found in chronically
\end{abstract}

tolerated transplants, but no more frequently than in older patients.

Many postoperative problems in the pediatric age group were the consequence of retardation of growth caused either by pre-existing uremia or by the need for high dose postoperative steroid therapy, orthopedic accidents such as femoral and vertebral fractures, and psychiatric complications which led to two suicides. In spite of these difficulties, the meaningful rehabilitation that was obtained in the chronic survivors makes us regard pediatric patients as favorable candidates for therapy with renal transplantation. Pediatrics, 47:548, 1971, KIDNEY FAILURE, GROWTH, OSTEOMALACIA, OSTEOPOROSIS, REHABILITATION, RENAL TRANSPLANTATION.
$\mathrm{F}$ or reasons that have never been very clearly stated, there was a widely held prejudice in the early days of renal homotransplantation against using this procedure for infants and children. In 1966, a report from our institution indicated that the pediatric patient was a favorable recipient in spite of special problems imposed by the necessity for immunosuppression during various phases of physical maturation. ${ }^{1} \mathrm{~A}$ number of subsequent publications have supported this view. ${ }^{2-7}$

In the present communication, a followup will be given of those 16 of the 22 recipients who were alive at the time of the 1966 report; all are still surviving. In addition, a number of special problems will be examined on the basis of a total series of 57 consecutive cases including the original ones in which follow-ups of $1 \frac{1 \%}{2}$ to $7 \%$ years are available.

\section{METHODS}

The 57 patients in this pediatric series were part of a larger total group of 189 recipients of all ages who were recently reported. ${ }^{8}$ In the more complete account, ${ }^{8}$ a number of specific questions were examined which will not be dealt with extensively in the pediatric subgroup herein described. These included the role of treatment with heterologous antilymphocyte globulin (ALG), the effect of thymectomy, the etiology of homograft glomerulonephritis, and the influence of this last complication upon the outcome.

The methodology of tissue typing, immunosuppression, and pathologic analysis were the same as in other publications. ${ }^{8-10}$ The first 29 patients were treated with azathioprine and prednisone. ${ }^{9}$ In the last 28 cases, horse antilymphocyte globulin ${ }^{8,10}$

\footnotetext{
(Received May 29; accepted for publication November 3, 1970.)
}

This work is supported by U. S. Public Health Service Grants AM-06344, AM-07772, RR-00051, AI-04152, RR-00069, AM-12148, HE-09110, and AI-AM-08898.

CORRESPONDENCE TO: (T.E.S.) Department of Surgery, University of Colorado Medical Center, 4200 East Ninth Ave., Denver, Colorado 80220 
was given as well and its administration usually restricted to the first 4 postoperative months. The surgical ${ }^{1,9}$ and urologic ${ }^{1,11}$ techniques were adapted to the individual patients. The most important deviation from the "standard adult" procedure was the use of a transperitoneal approach ${ }^{1,9}$ in 11 recipients who were either exceptionally small (10 years of age or younger, nine cases) or who presented special technical problems at the time of retransplantation (two cases). Bilateral recipient nephrectomy and splenectomy were performed in almost all cases either simultaneously with transplantation or before. ${ }^{9}$ Ten patients had transthoracic excision of their thymus glands, six before transplantation and four afterwards. ${ }^{8,9}$

All but two of the patients were resuscitated and/or maintained before transplantation with from one to more than 100 hemodialyses. In addition, 18 recipients had peritoneal dialysis at some time, usually early in their illness. Peritoneal dialysis was not used immediately before transplantation or afterwards because of the fear of intra-abdominal bacterial contamination. The renal homotransplantations were carried out between November, 1962, and January, 1969. The recipients were 3 to 12 years old in 23 cases and 13 to 18 years old in the other 34. A total of 68 kidneys were used. Four of the homografts were lost on the operating table from hyperacute rejection (one $\mathrm{ABO}$ blood group incompatibility and three apparent presensitizations). A fifth homograft was removed after 3 days be- cause of a technical complication. Consequently the number of organs that were studied chronically was 63 in 57 recipients and the number of late retransplantations was six.

\section{Survival}

\section{RESULTS}

Overall Mortality: Forty of the patients $(70.2 \%)$ are still alive after $1 \frac{1}{2}$ to $7 \frac{2}{3}$ years (Table I). Almost all the mortality was within the first year with eight deaths in the first half year and seven more in the succeeding 6 months. Two final deaths occurred after 17 and $19 \%$ months after which time the mortality ceased.

The current survival in children above and below 12 years (Table I) is almost identical (69.6\% and $70.6 \%$ respectively) and it is not different than in the recently reported total series that included adults as well as children. ${ }^{8}$ None of the 40 living pediatric recipients are on dialysis, but six are surviving on a second transplant after the first organ failed from 9 to 70 months after operation (mean $35_{\frac{1}{2}}^{1 / 2}$ months).

Survival According to Donor: There was a striking difference in survival between the 45 recipients whose first functioning kidney came from a blood relative (Table II) and the 12 recipients whose primary homograft came from a nonrelative (Table III). In the consanguineous cases (Table II), the present survival is $75.5 \%$. Moreover, only 4 of these 45 patients have required retransplantation. In contrast, 6 (50\%) of the 12 nonrelated recipients died

\section{TABLE I}

Survival Data

\begin{tabular}{lccccc}
\hline \multicolumn{1}{c}{ Data } & Total Cases & 3 months & 6 months & 12 months & Current \\
\hline Children (3-12 years) & 23 & 22 & 20 & 17 & $16^{*}(69.6 \%)$ \\
Adolescents (13-18 years) & 34 & 31 & 29 & 25 & $24 \dagger(70.6 \%)$ \\
Total Experience & 57 & 53 & 49 & 42 & $40(70.2 \%)$ \\
\hline
\end{tabular}

* One child (related recipient) died after 19 1/2 months.

$\dagger$ One adolescent recipient of a cadaveric kidney died after 17 months. 
TABLE II

Recipient Survival After 45 Consanguineous Renal Transplantations

\begin{tabular}{lccccc}
\hline \multicolumn{1}{c}{ Data } & Total Cases & 3 months & 6 months & 12 months & Current \\
\hline Children (3-12 years) & 15 & 14 & 13 & 13 & $12^{*}(80.0 \%)$ \\
Adolescents (13-18 years) & 30 & 27 & 26 & 22 & $22(73.3 \%)$ \\
Total Experience & 45 & 41 & 39 & 35 & $34(75.5 \%)$ \\
\hline
\end{tabular}

* One child died after 19 1/2 months.

and two of the six who remain are living on a second homograft (Table III).

Causes of Mortality: Three patients died from causes that have not yet been encountered in adult recipients. During the postoperative diuresis one adolescent recipient had an irreversible cardiac arrest which was the consequence of fluid and electrolyte mismanagement. Two other teenagers committed suicide, one by leaping through an eighth floor hospital window after 9 months and the other by first discontinuing immunosuppressive treatment and then when the homograft failed after a year by ingesting large quantities of water between hemodialyses.

The reasons for failure were not otherwise different than in adult kidney recipients. $^{8}$ These were usually due to toxic effects of the immunosuppressive agents (particularly steroids), failure of these agents to prevent recurrence of renal failure, or more commonly a combination of both factors. For example, one of the adolescents died from a reticulum cell sarcoma of the brain, a complication that has been recognized as being the consequence of immunosuppression. ${ }^{8}$ Infections by microorganisms for which highly specific antibiotic therapy is not available were directly responsible for another 10 deaths. Included were bacteria (usually gram-negative varieties), fungi (Aspergillus fumigatus, Histoplasma capsulatum, Nocardia asteroides), viruses (Mycoplasma pneumonia, Herpes zoster), and protozoa (Pneumocystis carinii). The lungs were the most common site of fatal infection (six examples) followed by the brain (two examples). The child who after 19\%2 months died of disseminated Herpes zoster had involvement of both the foregoing organs as well as infestation of the liver and small and large intestines; the direct cause of death was gastrointestinal exsanguination.

Miscellaneous causes of death were cerebral hemorrhages in two patients and a fatal pulmonary embolization in a third.

\section{Special Pediatric Problems}

Insofar as is known, azathioprine or a short course of antilymphocyte globulin has no detectable effect upon growth and maturation or upon psychological development. In contrast, prednisone can be responsible for very severe somatic and psychic problems in pediatric patients as has been emphasized in past publications. ${ }^{1,9,10}$ The average daily prednisone doses at the end of the first post-transplant year for the 42 patients in the present study who lived for this long was $.32 \mathrm{mg} / \mathrm{kg}$. Since the magnitude of the resulting problems must be taken into consideration in discussing transplantation in the young, such complications will be discussed in detail.

Growth: After transplantation the majority of the patients became available for long term observation of growth patterns. Because steroid treatment often induced obesity and thereby gave a false impression of true growth, the weight changes will not be recorded. Instead, growth will be expressed exclusively in terms of height.

Only 3 of the 18 patients who were 17 or 18 years of age prior to transplantation 
were below the third percentile for a 16 year-old. Consequently, most of these older patients had already been spared the threat of severe dwarfism. The same did not apply to the other 39 recipients who were 16 years or younger and who were still in more active phases of physical maturation. Moreover, an additional problem in the younger patients was that of pre-existent stunting since 25 of the 39 recipients were already below the third height percentile when they were first evaluated.

Thirty of the 39 patients treated before the age of 16 years became available for observation for $1 \frac{112}{2}$ to $7 \frac{1}{3}$ years (average 4 years). Of 12 who were above the third height percentile before operation, nine ultimately maintained or improved their rank and in fact all nine are now near the 50th percentile. The other three lost ground, but in two instances this was transient, lasting only a year. The exceptional patient of the latter three was at the 40 th percentile when he was given a maternal homograft at the age of 3 years. Although he has grown 23 cm (9 in.) in the seven subsequent years, his height relative to his age has slowly decreased until he is now below the third percentile (Fig. 1).

The 18 children who began the postoperative period below the third height percentile and who survived chronically, tended to remain small for a long time postoperatively. Specifically, only four grew enough in the first 12 months after transplantation to improve their relative position on the growth curve. During the same time, an- other four actually lost ground. The 10 others remained about the same. In the second postoperative year, 8 of the 18 patients had a growth spurt which elevated their height above the third percentile (Fig. 2) whereas the other 10 either remained the same (seven examples) or regressed (three examples). There have been 10 patients in the group of 18 who have been followed from $2 \frac{1 \%}{2}$ to $7 \frac{1}{3}$ years; six have grown to a normal height (10 to 60th percentile), whereas the other four have remained below the third percentile. The four stunted children collectively have excellent renal function and low current steroid doses. However, in each of the four cases the duration of earlier heavy prednisone treatment was protracted.

Failure to have accelerated growth in the first years after renal transplantation was not necessarily a discouraging sign, since surprising increases in height have occurred rather late in adolescence. Between the ages of 16 and 19 years, five of our recipients grew from a dwarfed to a normal height within 12 to 18 months. One of these recipients was 5 years post-transplantation before her height rose above the third percentile.

ORTHOPEDic Complications: With chronic uremia, there are profound changes in mineral metabolism ${ }^{1,9,12,13}$ which often result in osteoporosis and osteomalacia. Three of the teenagers in this series had severe consequent orthopedic complications which predated renal transplantation. One had bilateral slipped femoral epiphyses and the

TABLE III

Recipient Survival After 12 Nonrelated Renal Transplantations

\begin{tabular}{lccccc}
\hline \multicolumn{1}{c}{ Data } & Total Cases & 3 months & 6 months & 12 months & Current \\
\hline Children (3-12 years) & 8 & 8 & 7 & 4 & $4^{*}$ \\
Adolescents (13-18 years) & 4 & 4 & 3 & 3 & $2 \dagger$ \\
Total Experience & 12 & 12 & 10 & 7 & $6(50 \%)$ \\
\hline
\end{tabular}

* The homografts in two children failed after 9 and 30 months; both are surviving on a second transplant.

$\dagger$ The homograft failed in one adolescent after one year with subsequent death. 


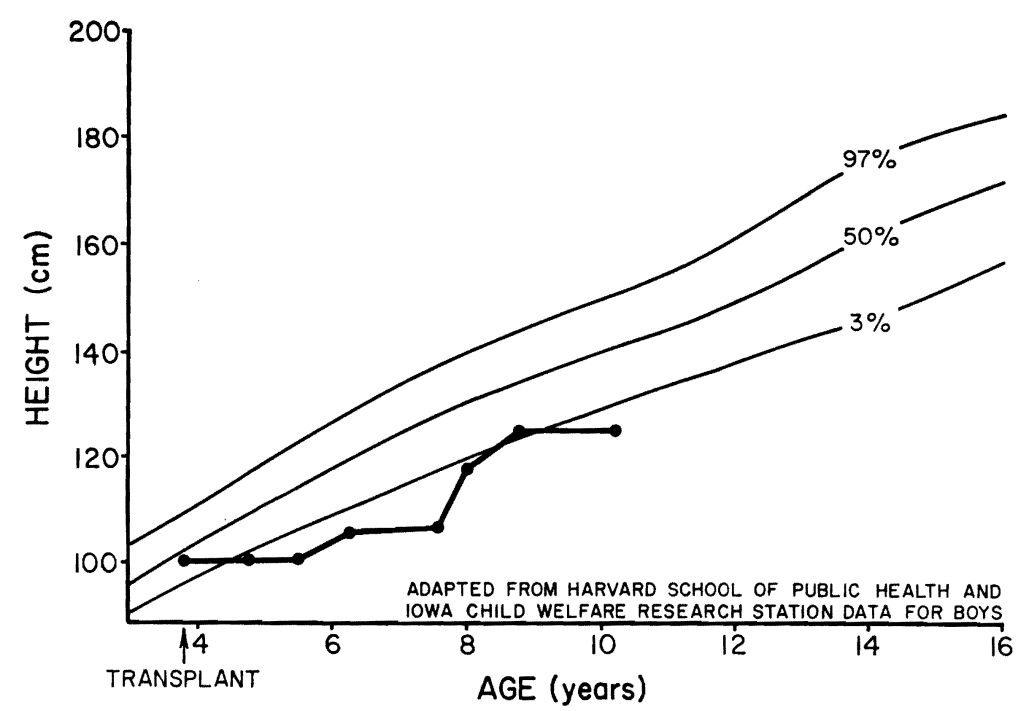

Frg. 1. The height percentile growth curve of a 3-year-old boy who was in the 40 th percentile at the time of renal homotransplantation. Although growing $23 \mathrm{~cm}$ over the subsequent $6 \%$ years, the growth rate was subnormal and he is now below the third percentile.

other two had severe genu valgum ("knock knees"). All three patients underwent successful renal homotransplantation and 5 to 23 months later had standard orthopedic operative repairs of their deformities.

Six other children who received renal homografts at the ages of 11 to 18 years developed potentially crippling orthopedic complications afterwards. In five of the patients there was atrophy and unilateral or bilateral fracture of the femoral head and/or neck. ${ }^{1,3,9,14-16}$ The sixth patient had compression fractures of multiple lower thoracic vertebrae. These femoral and vertebral fractures occurred relatively early after transplantation (4 to 22 months, average 10 months) during or not long after the time of heavy steroid therapy. In five of the six cases obesity was a contributory factor. No surgical treatment was advised for the resulting deformities. In time, healing occurred coincident with bone remineralization and improvement of the radiographic appearance of the rest of the skeleton.

This kind of skeletal complication has been seen in adults as well as in children ${ }_{1,9,14-16}$ but the consequent morbidity has been particularly annoying in the pediatric age group. Since transplantation the six patients described above have been followed for $2^{1 / 3}$ to 7 years. The time since the onset of the bone deformity has been $1 \frac{1}{2}$ to $6 / 3$ years. In order to attend high school or college, special provisions for transportation have often been required. Moreover, the necessity for prolonged crutch or cane walking at this time of life has caused many complaints.

Behavion Disorders: The recipients who were 12 years old or younger at the time of transplantation were free from severe psychiatric manifestations and have remained so for as long as $7 \frac{1}{3}$ years. The major behavioral problem, by far, was the control of steroid-induced overeating during the early postoperative period.

In contrast, there were a number of serious problems with the adolescents who were far more preoccupied with the effects of steroid-induced changes in appearance, with pre-existing physical liabilities such as short stature, and with the need to be dependent upon drugs for continuing life. In many such patients the loss of physical at- 
tractiveness seemed tantamount to a loss of self-esteem and the two suicides were apparently a direct consequence. The boys who deliberately ended their lives by leaping from a hospital window and by systematic over-ingestion of fluid had been recently repudiated by girl friends. In other teenaged patients, even trivial improvements such as a centimeter of growth or a partial clearance of acne often led to a long lasting improvement in emotional outlook. None of the patients in this resilient age who survived beyond a year and a half has been left with a permanen' psychosis.

\section{Other Complications}

A number of nonfatal complications occurred at about the same frequency as in adult patients including cardiac arrest from electrolyte disequilibrium, ${ }^{9}$ postoperative intestinal obstruction, ${ }^{17}$ obstruction or fistula formation of the homograft ureter, ${ }^{11}$ and a variety of infections. ${ }^{8}$ Certain other complications were seen somewhat less frequently than in older renal recipients. These included steroid-induced diabetes (7\%), severe gastrointestinal hemorrhage
(7\%) in one case necessitating subtotal gastrectomy, pulmonary embolization (7\%), and pancreatitis (1.8\%).

\section{Control of Rejection}

Within the first 3 postoperative months, $42(74 \%)$ of the 57 patients experienced a rejection episode which was always at least partially reversible and in most instances completely so. There were no distinguishing clinical features of rejection in the patients who were 12 years or younger in comparison with the teenagers or with adults. If anything, the young children had rejection crises at a slightly earlier time (average 12.5 days in children versus 18.9 days in adolescents) rather than late as has been reported by T. C. Moore and D. M. Hume. ${ }^{5}$

In most cases, HL-A antigens were measured in both the donor and recipient by Dr. Paul Terasaki of Los Angeles using a lymphocytotoxicity test. The quality of the antigenic match was then expressed by the well known A-D alphabetical scale. As has been fully documented in a recent publication, ${ }^{8}$ there was no correlation between

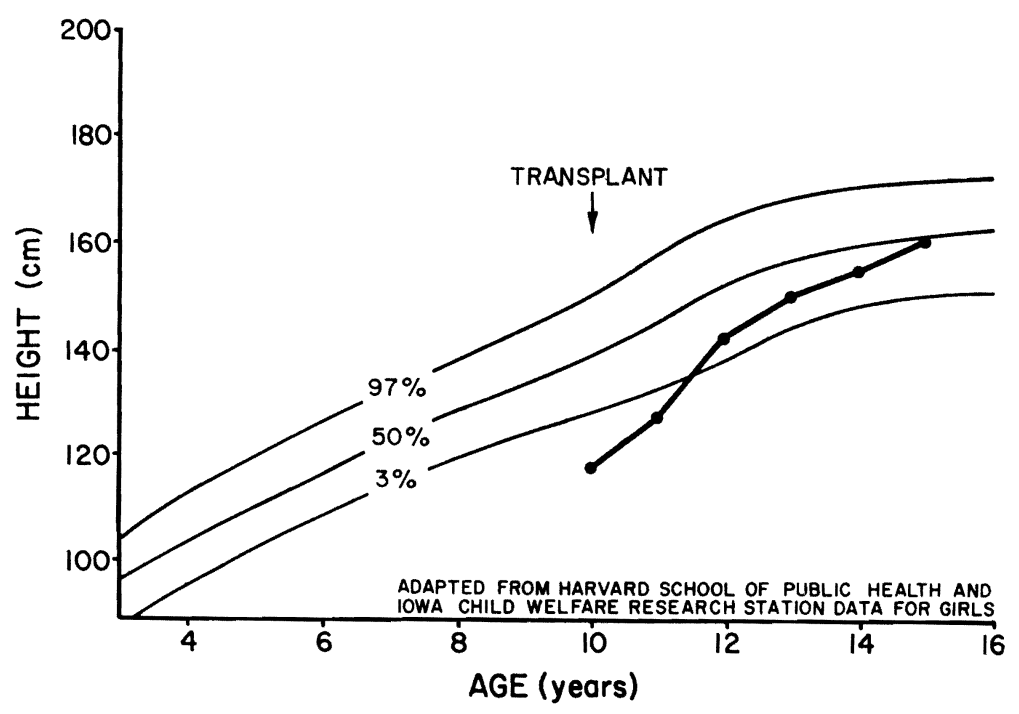

FIG. 2. The height percentile growth curve in a 10-year-old girl who was far below the third percentile at the time of renal homotransplantation. After operation, steroids were gradually tapered. She reached the 50th height percentile 5 years after surgery. 
these matches and the outcome after transplantation from parents or more distant relatives. Since the patients of the present report were taken from the larger series and since most of them received kidneys from the aforementioned kinds of donors, it was not surprising that there was similar lack of correlation.

\section{Durability of the Homografts}

Earlier it was pointed out, first, that all the deaths occurred within the first $19 \%$ months, and second, that a number ( six examples) of these 17 early failures were not contributed to by recurrent uremia. The remaining 40 patients have provided information about the duration of function that can be expected from transplanted kidneys.

RELATEd Homografts: The primary graft was from a family member in 34 of the 40 recipients who are still surviving. Four of these transplants eventually failed after 23 , 28,67 , and 70 months necessitating retransplantation. Thirty other original consanguineous kidneys are still supporting life after an average of $4 \frac{1}{2}$ years. Function of 23 of the remaining 30 consanguineous homografts is still good to normal (BUN less than $25 \mathrm{mg} / 100 \mathrm{ml}$, creatinine less than $1.2 \mathrm{mg} / 100 \mathrm{ml}$ ). The other seven transplants have subnormal but stable function.

Nonrelated Homografts: Of the 12 recipients of nonrelated kidneys, six remain alive after 18 to 54 months. Four of these patients still have good to excellent function of their original transplants after $18,24,26$, and 31 months. The two others received intrafamilial kidneys when the original nonrelated organs were rejected after 9 and 30 months.

Late Retransplantations: There were six patients who had slow deterioration of their primary homografts (four consanguineous and two cadaveric). In five of the six cases, second kidneys were given by another family member, while in the sixth a cadaveric organ was used. The six second transplants have good to normal function after follow-ups of $2 \frac{1}{2}$ to 44 months.

Hypertension and Proteinuria: A number of patients were classified as having good renal function in spite of the fact that they had either hypertension or proteinuria. An idea of the frequency of hypertension was obtained by examining the records of the 42 recipients who lived for at least 1 year. At the end of 12 post-transplantation months, 16 (38\%) of the 42 survivors either had blood pressures of $130 / 90$ or higher or else required significant quantities of antihypertensive drugs to keep their blood pressures below this level. In three cases the management of the hypertension was exceedingly troublesome.

One year postoperatively the urine of 9 of the same 42 patients contained more than $0.25 \mathrm{gm}$ of protein per liter. This degree of proteinuria affected four of the seven cadaveric recipients. In contrast only 5 of 35 patients with related kidneys had this complication.

\section{The Question of Glomerulonephritis}

In two recent publications from this institution, ${ }^{8,18}$ it was shown that about half of chronically functioning homografts have obvious glomerulonephritis of the kinds caused in the experimental model by antiglomerular basement membrane antibody (Masugi-like nephritis) or by the lodgement of soluble antigen-antibody complexes in the renal microvasculature (complex nephritis). Evidence was presented ${ }^{8}$ that the most common cause of homograft glomerulonephritis was slow rejection mediated primarily by humoral antibodies.

In support of this contention were the facts that: (1) the diagnosis of homograft glomerulonephritis was made in some cases in which the original host disease had not been of an autoimmune etiology; (2) good histocompatibility matching (as in double haplotype identical siblings) was associated with a decreased rate of glomerulonephritis; (3) histoincompatibility predisposed to glomerulonephritis as shown by the higher incidence in unrelated as opposed to related cases. On the other hand, there were many patients in whom transplanted organs apparently were adversely affected by the continuation of the same disease that had destroyed the native kidneys. The evidence 
favoring this sequence of events was that: (1) the incidence of glomerulonephritis in the transplants was higher if this was the original disease; (2) glomerular changes in the grafts were very often ( 23 well documented examples) a faithful or nearly faithful anatomic recapitulation of the disease that had necessitated transplantation in the first place.

The pediatric patients of the present study were a subgroup of the larger series of 189 cases alluded to above. ${ }^{8}$ The overall incidence of glomerulonephritis in the combined children and adolescerts was approximately the same as in the adults. Included in the pediatric collection were 5 of the 23 examples of homograft glomerulonephritis that was either very similar or else identical to that which had destroyed the native kidneys. Thus the contention of Williams, Lee, and $\mathrm{Hume}^{2}$ that children were peculiarly susceptible to homograft glomerulonephritis "transmitted" as a result of the original autoimmune disorder of the host was not well supported from these observations since all varieties of homograft glomerular damage seen in children have been about as well represented in adults.

\section{Ultimate Rehabilitation}

The natural exuberance of the young which was responsible for many emotional problems in early convalescence became an advantage for those who achieved chronic survival. None of the 40 living patients has retired from life. Five of the younger children attend elementary school full time; several are active in scouting. Twelve teenagers attend secondary schools. Eight of the patients have entered college and two have passed on to graduate school. Eight more of the recipients have full-time jobs after having completed a high school or college education. Five females and four males have married. Three of the girls have had babies by normal vaginal delivery and one boy has a normal infant.

Only 3 of the 40 survivors have had academic difficulties which required unusual educational provisions. In these cases, the patients were either behind in school work at the time of transplantation, fell behind subsequently because of the need for repeated hospitalization, or suffered from the handicap of slight mental retardation.

\section{DISCUSSION}

Since the inception of the clinical transplantation program at the University of Colorado in 1962, pediatric patients have been considered prime candidates for therapy. The first person to be treated with renal homotransplantation was a 12 -year-old child who is still alive and in perfect health almost 8 years later. The same positive attitude has prevailed with the transplantation of other organs such as the liver and heart. ${ }^{1}$

Other authors have expressed the opinion that rejection occurs later and/or in a more virulent form in the pediatric age group 5 and that the renal homografts of these chil dren are more susceptible to glomerulonephritis if this was the original host disease. ${ }^{2,5}$ There was no indication from our experience that such problems of immunologic control were either qualitatively or quantitatively different in younger patients as opposed to adults.

This does not mean that pediatric kidney recipients can be managed exactly the same as adults. ${ }^{19}$ For one thing, special surgical techniques may be required if adult organs are to be transplanted to undersized children. ${ }^{1,9}$ If good renal function is obtained, precautions must be taken during the subsequent diuresis to maintain proper fluid and electrolyte balance. Failure to provide this kind of meticulous care cost the life of one patient of the presently reported series.

After the immediate effects of operation had passed, the most specific problems seen in children as well as in adolescents derived in one way or another from the skeletal system either because of actual deformity or else because of failure of growth. Orthopedic complications, as well as growth cessation, were obviously partly related to the pre-existing uremia, and the consequent disturbance of mineral metabolism and maturation. In addition, the need to give high doses of steroids for long periods after trans- 
plantation was a factor of at least equivalent importance. In the quantities : ased, the prednisone could be observed to halt growth in some of the patients. It also caused other cosmetic disfiguration which was less well tolerated by young people than by more mature individuals. Two of the adolescents committed suicide, one in an occult and the other in an open manner.

In spite of special physical and emotional problems, the pediatric patients who survived chronically embraced their new lives with an ebullience greater than that in most comparable adult patients. They returned to school in high numbers, became employed, and in nine instances were ultimately married. The orthopedic complications alluded to above were eventually compensated for in one way or another, even though they have been a continuing source of long term morbidity. Moreover, a number of recipients who were stunted in growth either because of chronic uremia or because of heavy steroid treatment posttransplantation had growth spurts at a surprisingly late age, as long as 5 years after their operation.

Although satisfactory growth was finally obtained in the vast majority of cases, six of the chronically surviving recipients are relative dwarfs when viewed as statistics on a percentile height graph. However, in none of these cases has the presence of small stature been a serious handicap in day to day life. The most diminutive of these patients is a young woman who received renal transplantation at the age of 17 . Now, 5 years later, she is a charming 4 feet 10 inches and the mother of a normal 3-yearold infant.

\section{REFERENCES}

1. Starzl, T. E., Marchioro, T. L., Porter, K. A., Faris, T. D., and Carey, T. A.: The role of organ transplantation in pediatrics. Pediat. Clin. N. Amer., 13:381, 1966.

2. Williams, G. M., Lee, H. M., and Hume, D. M.: Renal transplants in children. Transplantation Proceedings, 1:262, 1969.

3. Williams, G. M., and Hume, D. M.: Renal Homotransplantation. In Mustard, W. T., Rav- itch, M. M., Snyder, W. H., Jr., Welch, K. J., and Benson, C. D. Ed.: Pediatric Surgery II. Chicago: Year Book Medical Publishers, Inc., 1969.

4. Martin, L. W., Gonzalez, L. L., West, C. D., Swartz, R. A., and Sutorius, D. J.: Homotransplantation of both kidneys from an anencephalic monster to a 17 pound boy with Eagle-Barrett syndrome. Surgery, 66:603, 1969.

5. Moore, T. C., and Hume, D. M.: The period and nature of hazard in clinical renal transplantation: II. The hazard to transplant kidney function. Ann. Surg., 170:12, 1969.

6. Fine, R. N., Korsch, B. M., Stiles, Q., Riddell, H., Edebrock, H. H., Brennan, L. P., Grushkin, C. M., and Liberman, E.: Renal homotransplantation in children. J. Pediat., 76: 347, 1970.

7. Potter, D., Belzer, F. O., Rames, L., Holliday, M. A., Kountz, S. L., and Najarian, J. S.: The treatment of chronic uremia in childhood: I. Transplantation. Pediatrics, 45: 432, 1970.

8. Starzl, T. E., Porter, K. A., Halgrimson, C. G., Andres, G., Hurwitz, R., Giles, G., Terasaki, P. I., Penn, I., Lilly, J. R., Starkie, S. J., Schroter, G. P. J., and Putnam, C. W.: Long term survival after renal transplantation in humans: With special reference to histocompatibility matching, thymectomy, homograft glomerulonephritis, heterologous ALG, and recipient malignancy. Ann. Surg. 172:437, 1970.

9. Starzl, T. E.: Experience in Renal Transplantation. Philadelphia: W. B. Saunders Co., 1964.

10. Starzl, T. E., with the assistance of C. W. Putnam: Experience in Hepatic Transplantation. Philadelphia: W. B. Saunders Co., 1969.

11. Starzl, T. E., Groth, C. G., Putnam, C. W. Penn, I., Halgrimson, C., Flatmark, A., Gecelter, L., Brettschneider, L., and Stonington, O. G.: Urological complications in 216 human recipients of renal transplants. Ann. Surg., 172:1, 1970.

12. Liu, S. H., and Chu, H. I.: Studies of calcium and phosphorus metabolism with special reference to the pathogenesis and effect of dehydrotachysterol (A.T. 10) and iron. Medicine, 22:103, 1943.

13. Stanbury, S. W.: Bone disease in uremia. Amer. J. Med., 44:714, 1968.

14. Bravo, J. F., Herman, J. H., and Smyth, C. J.: Musculoskeletal disorders after renal homotransplantation. Ann. Intern. Med., 66:87, 1967. 
15. Cruess, R. L., Blennerhassett, J., MacDonald, F. R., MacLean, L. D., and Dossetor, J.: Aseptic necrosis following renal transplantation. J. Bone Joint Surg., 50:1577, 1968.

16. Irby, R., and Hume, D. M.: Joint changes observed following renal transplants. Clin. Orthop., 57:101, 1968.

17. Penn, I., Brettschneider, L., Simpson, K. M., Martin, A., and Starzl, T. E.: Major colonic problems in human homotransplant recipients. Arch. Surg., 100:61, 1970.

18. McPhaul, J. J., Jr., Dixon, F. J., Brettschneider, L., and Starzl, T. E.: Immunofluorescent examination of biopsies from long term renal allografts. New Eng. J. Med., 282:412, 1970.

19. Riley, C. M.: Thoughts about kidney transplantation in children. J. Pediat., 65:797, 1964. 